\title{
The elusive parathyroids
}

\author{
Ranil Fernando \\ Department of Surgery, Faculty of Medicine, University of Kelaniya, Ragama, Sri Lanka.
}

Correspondence: Professor Ranil Fernando

e-mail: ranilfern@sltnet.lk

D) https://orcid.org/0000-0003-4479-1716

\section{Introduction}

The parathyroids are four small glands in the neck in close proximity to the thyroid gland and their main function is calcium homeostasis. Parathyroid disorders are common clinical entities encountered in practice. Primary hyperparathyroidism (PHPT) is by far the commonest disorder diagnosed in clinical practice. Worldwide studies show an annual incidence of PHPT of 20 cases per 100,000 people with an estimated prevalence in the general population of $0.5 \%$ to $1 \%$ increasing with age over $2 \%$ in both sexes by the age of $55(1-3)$.

The precise incidence of parathyroid disorders in Sri Lanka is unknown and there is a noticeable paucity of literature on parathyroid disorders in Sri Lanka. Experienced clinicians have noted that in clinical practice; the diagnosis of PHPT is definitely less than figures quoted in the world literature. This appears to be a phenomenon seen in other Asian countries including India, China and the Middle East (3-5).

There are several reasons for this, perhaps we are not looking for it diligently or the disease pattern has changed from overt disease to asymptomatic disease as seen in the western countries or the diagnostic facilities especially in the government sector are inadequate for the diagnosis to be made accurately. It is likely that combinations of these factors are at play. It seems that the Parathyroid disease remains and elusive entity in clinical practice in Sri Lanka and in developing countries.

\section{The need to diagnose and treat}

In the western countries, wide-spread screening in the 1970s increased the diagnosis of PHPT

especially the asymptomatic disease dramatically (6). Hence the asymptomatic patients and the patents with mild symptoms became the predominant clinical patterns in those countries. The picture in Asia remains undetermined, yet in India the picture is same as before with a significant number of patients having overt disease (3).

Around $85-90 \%$ of PHPT is due to a single adenoma and surgery is curative and relieves symptoms even if they are mild and non-specific such as fatigue; and this recovery is early in the postoperative period (7-9). If a Patient has overt symptoms they are likely to be referred for surgery. The issue is with patients who are asymptomatic or have only mild nonspecific symptoms. The experience is that PHPT and other parathyroid diseases are not detected in the age group as it should be done at a point of time when they can be prevented from having a long-term morbidity and the very rare occurrence of mortality. Even if surgery is not undertaken or is not recommended; medical management with targeted medical therapy using amino-bisphosphonates for skeletal protection and cinacalcet for lowering serum calcium needs to be considered. This requires accurate diagnosis initially. This means that even a selective screening policy must be employed in Sri Lanka and in other developing countries. This raises the question of who should be offered screening. There are some obvious candidates for screening. They include:

- Patients with recurrent, multiple or bilateral urinary calculi

- Patients with recurrent acute pancreatitis

- Patients over 50 years with persistent bone pain without an obvious cause 
- Elderly patients with unexplained fatigue and neuropsychological symptoms

These patients will need the accurate assessment of serum ionized calcium levels. Ideally at least 2 levels if the results are marginal. If they have proven hypercalcaemia and without evidence of an underlying malignancy, they should have a serum parathormone assay (PTH).

Urolithiasis is the original and the commonest manifestation in PHPT. It is not uncommon to come across patients with multiple bilateral or recurrent urinary tract calculi who have not had an assessment of their calcium status. This may be due to many factors including non-availability of facilities, but it is likely that some of these patients are having PHPT. Several studies have shown that about 5\% of patients with urolithiasis have PHPT (10-12).

There is very little doubt that screening for PHPT and treating it prevents significant morbidity and mortality hence all attempts must be made to 'capture' the elusive parathyroid and treat it. There are several guidelines (13) that will help in easy decision making. Every effort must be made to detect and treat parathyroid disease particularly PHPT.

\section{References}

1. Siperstein AE, Berber E. The prevalence of undiagnosed and unrecognized primary hyperparathyroidism: a population-based analysis from the electronic medical record DM Press, Surgery, 2013; 154: 1232-7.

2. Minisola S. Primary hyperparathyroidism is one of the three most frequent endocrine disorders, typically diagnosed in the years following menopause and with advancing age. J Endocrinol Invest, 2012; 35.

3. Pradeep PV, Jayashree B, Mishra Anjali, Mishra SK. Systematic Review of Primary Hyperparathyroidism in India: The Past, Present, and the Future Trends; International Journal of Endocrinology, May 2011: 2011; pages 7 .
4. Zhao L, et al. The changing clinical patterns of primary hyperparathyroidism in Chinese patients: data from 2000 to 2010 in a single clinical center. JClin Endocrinol Metab, 98: 721-28.

5. Bismar HA, El-Bakry AA Primary hyperparathyroidism. Saudi MedJ, (11): 1214-18.

6. Bilezikian John P. and Silverberg Shonni J. Asymptomatic Primary Hyperparathyroidism. The New England Journal of Medicine, 2004; 350: (17): 1746-51.

7. Murray Sara E, et al. Timing of Symptom Improvement after Parathyroidectomy for Primary Hyperparathyroidism Surgery. Dec 2013; 154(6): 1463-69. Doi. 10.1016/j.surg. 2013.09.005.

8. Pasieka Janice L, Parsons Louise L. Prospective Surgical Outcome Study of Relief of Symptoms following Surgery in Patients with Primary Hyperparathyroidism. World $J$. Surg, 1998; 22: 513-19.

9. Chan AK, Duh QY, Katz MH, Siperstein AE, Clark O H. Clinical manifestations of primary hyperparathyroidism before and after Parathyroidectomy. A case-control study. Ann Surg, Sep 1995; 222(3): 402-14.

10. Sharma Sumit, et al. Prevalence and predictors of primary Hyperparathyroidism among patients with urolithiasis. Endocrine practice, Nov 2017; 23(11). 1311-15.

11. Suh JM, Cronan JJ, Monchik JM. Primary hyperparathyroidism: Is there an increased prevalence of renal stone disease? AJR Am J Roentgenol, 2008; 191: 908-911.

12. Anurag Ranjan Lila, et al. Renal manifestations of primary hyperparathyroidism. Indian J Endocrinol Metab, 2012; 16: $258-62$.

13. Khan AA, Hanley DA, Bilezikian JP, et al. Primary hyperparathyroidism: review and recommendations on evaluation, diagnosis, and management. A Canadian and international consensus. Osteoporosis Int, 2017; 28(1): 1-19. 